\title{
Aspirin in coronary artery surgery: 1-year results of the Aspirin and Tranexamic Acid for Coronary Artery Surgery trial
}

\author{
Paul S. Myles, MD, DSc, ${ }^{\text {a,b }}$ Julian A. Smith, MS, FRACS, ${ }^{\text {,cc }}$ Jessica Kasza, PhD, ${ }^{\text {b }}$ \\ Brendan Silbert, MBBS, FANZCA, ${ }^{\mathrm{d}}$ Mohandas Jayarajah, MBBS, FRCA, \\ Thomas Painter, MBChB, FANZCA, ${ }^{\mathrm{f}}$ D. James Cooper, MD, FCICM, ${ }^{\mathrm{a}, \mathrm{b}}$ Silvana Marasco, PhD, FRACS,, , b \\ John McNeil, PhD, FRACP, ${ }^{\mathrm{b}}$ Jean S. Bussières, MD, FRCPC, ${ }^{\mathrm{g}}$ Shay McGuinness, MBChB, FANZCA, ${ }^{\mathrm{h}}$ \\ Matthew T. V. Chan, PhD, MBBS, ${ }^{\mathrm{i}}$ Sophie Wallace, $\mathrm{MPH},{ }^{\mathrm{a}, \mathrm{b}}$ and Andrew Forbes, $\mathrm{PhD},{ }^{\mathrm{b}}$ for the ATACAS \\ investigators and the ANZCA Clinical Trials Network*
}

\section{ABSTRACT}

Background: Aspirin may reduce the risk of vascular graft thrombosis after cardiovascular surgery. We previously reported the 30-day results of a trial evaluating aspirin use before coronary artery surgery. Here we report the 1-year outcomes evaluating late thrombotic events and disability-free survival.

Methods: Using a factorial design, we randomly assigned patients undergoing coronary artery surgery to receive aspirin or placebo and tranexamic acid or placebo. The results of the aspirin comparison are reported here. The primary 1-year outcome was death or severe disability, the latter defined as living with a modified Katz activities of daily living score $<8$. Secondary outcomes included a composite of myocardial infarction, stroke and death from any cause through to 1 year after surgery.

Results: Patients were randomly assigned to aspirin (1059 patients) or placebo (1068 patients). The rate of death or severe disability was $4.1 \%$ in the aspirin group and $3.5 \%$ in the placebo group (relative risk, $1.17 ; 95 \%$ confidence interval, $0.76-1.81 ; P=.48)$. There was no significant difference in the rates of myocardial infarction $(P=.11)$, stroke $(P=.086)$, or death $(P=.24)$, or a composite of these cardiovascular end points $(P=.68)$. With the exception of those with a low European System for Cardiac Operative Risk Evaluation score $(P=.03)$, there were no interaction effects on these outcomes with tranexamic acid (all tests of interaction $P>.10$ ).

Conclusions: In patients undergoing coronary artery surgery, preoperative aspirin did not reduce death or severe disability, or thrombotic events through to 1 year after surgery. (J Thorac Cardiovasc Surg 2019;157:633-40)

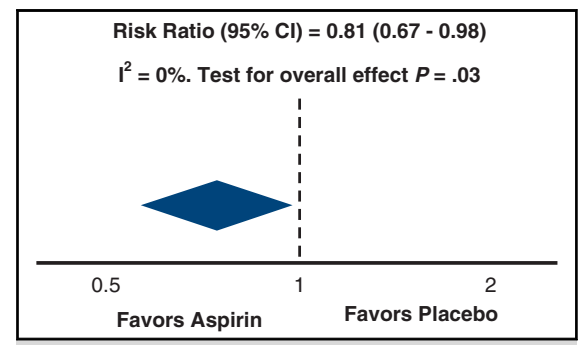

Updated meta-analysis (8 trials, 3307 patients): The risk ratio for myocardial infarction up to 1 year after surgery. Adapted from reference 21 with permission from the authors.

\section{Central Message}

Aspirin can be safely continued in most patient undergoing coronary artery surgery, but this does not seem to reduce longer-term thrombotic risk or improve disability-free survival.

\section{Perspective}

Patients undergoing coronary artery surgery are mostly concurrently treated with aspirin, and this does not seem to increase the risk of bleeding complications. Aspirin is believed to promote graft blood flow and possibly prevent late graft thrombosis. This would manifest as a reduction in myocardial infarction and heart failure, with improved disability-free survival after surgery.

See Editorial page 641.

See Editorial Commentary page 643.

\footnotetext{
From the ${ }^{a}$ Alfred Hospital, Melbourne, Australia; ${ }^{b}$ Monash University, Melbourne, Australia; ${ }^{\mathrm{C}}$ Monash Medical Centre, Clayton, Australia; ${ }^{\mathrm{d}}$ St Vincent's Hospital, Fitzroy, Australia; ${ }^{\text {e}}$ South West Cardiac Centre, Derriford Hospital, Plymouth, United Kingdom; ${ }^{f}$ Royal Adelaide Hospital and Discipline of Acute Care Medicine, University of Adelaide, Adelaide, Australia; ${ }^{g}$ Institut Universitaire de Cardiologie et de Pneumologie de Québec, Quebec City, Quebec, Canada;

${ }^{\mathrm{h}}$ Auckland City Hospital, Auckland, New Zealand; and ${ }^{\mathrm{i}}$ The Chinese University of Hong Kong, Hong Kong.

The study sponsor was the Alfred Hospital, Melbourne, Australia. The study was supported by grants from the Australian National Health and Medical Research Council (NHMRC, ID 334015 and 1009203), the Australian and New Zealand
}

College of Anaesthetists, and the UK National Institute for Health Research. Paul Myles is supported by an Australian NHMRC Practitioner Fellowship.

*Participating centers and investigators in the Aspirin and Tranexamic Acid for Coronary Artery Surgery (ATACAS) Trial are listed in the Online Data Supplement. Received for publication April 16, 2018; revisions received July 7, 2018; accepted for publication Aug 21, 2018; available ahead of print Nov 3, 2018.

Address for reprints: Paul S. Myles, MD, DSc, Department of Anaesthesia and Perioperative Medicine, Alfred Hospital, Commercial Rd, Melbourne, Victoria 3004, Australia (E-mail: p.myles@alfred.org.au).

$0022-5223 / \$ 36.00$

Copyright (C) 2018 by The American Association for Thoracic Surgery https://doi.org/10.1016/j.jtcvs.2018.08.114 


\section{Abbreviations and Acronyms}

$\mathrm{ADL}=$ activities of daily living

ATACAS $=$ Aspirin and Tranexamic Acid for

Coronary Artery Surgery

MACE = major adverse cardiovascular events

Scanning this QR code will take you to the article title page to access supplementary information.

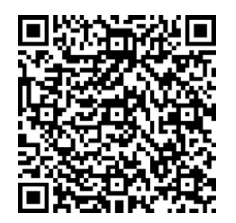

The risks and benefits of continuing aspirin in coronary artery surgery have been debated for many years. ${ }^{1}$ In 2016, the aspirin results of the Aspirin and Tranexamic Acid in Coronary Artery Surgery (ATACAS) trial were reported. ${ }^{2}$ We found that continuing aspirin up until the day of surgery did not reduce thrombotic complications or death, but also did not increase bleeding, transfusion requirements, or any other complications through to 30 days after surgery. ${ }^{2}$

Coronary graft failure occurs in up to $25 \%$ of saphenous vein grafts and $5 \%$ of arterial grafts at 1 year after surgery, but the clinical consequences vary according to the type, location, and reason for the failed graft. ${ }^{3}$ Intraoperative and postoperative low flow states, vasospasm, and endothelial injury may promote early graft thrombosis and so place a patient at increased risk of early and late cardiac events. Secondary prevention using aspirin and more potent antiplatelet agents reduce the incidence of late cardiac events ${ }^{4}$ and related benefits may be provided by preoperative or immediate postoperative aspirin therapy, ${ }^{5-7}$ but results from small trials have had mixed results. ${ }^{5,8,9}$ We thus planned a 1-year follow-up study to determine whether preoperative aspirin reduced the long-term risk of death or disability, and myocardial infarction and stroke after cardiac surgery.

\section{METHODS \\ Study Design}

The rationale and design of the ATACAS trial, ${ }^{10}$ the 30-day results of the aspirin comparison, ${ }^{2}$ and 30-day results of the tranexamic acid comparison, ${ }^{11}$ have been reported previously. ATACAS was an international, randomized, double-blind, $2 \times 2$ factorial trial evaluating preoperative aspirin and tranexamic acid at 22 centers in 6 countries to separately assess safety and effectiveness of aspirin and tranexamic acid in patients undergoing coronary artery surgery. In July 2008, the members of the ATACAS steering committee incorporated a 1-year follow-up that included measurement of patient disability (see below) in the study procedures. The long-term follow-up was approved by the ethics committee at 20 of the 22 participating centers, and patients provided signed written informed consent before enrollment.

\section{Patient Selection}

Eligible participants included adults who were at increased risk of major complications and who were having on-pump or off-pump coronary artery surgery, with or without cardiac valvular or other procedures. For the aspirin study cohort, patients had to have their aspirin medication stopped for at least 4 days or otherwise not receiving this medication. Other eligibility criteria are detailed in the Online Data Supplement.

\section{Study Medication}

Bayer Pharma (Leverkusen, Germany) provided the aspirin and matched placebo tablets used in the study. Oral enteric-coated aspirin, $100 \mathrm{mg}$, (or matched placebo) was administered approximately 2 to 3 hours before surgery. All patients received open-label aspirin in the postoperative period, and for this to continue postdischarge in accordance with established guidelines. Some patients, mostly those with chronic or intermittent atrial fibrillation, also received other antiplatelet or anticoagulation according to local practices.

\section{Randomization, Blinding, and Data Quality}

Patients were randomly assigned to treatments with oral aspirin or matched placebo, tranexamic acid or placebo ( $0.9 \%$ saline), or aspirin and tranexamic acid 1:1:2 stratified by site and whether surgery was performed on- or off-pump in permuted blocks, using a computergenerated code. The surgical team and all other clinical staff members were blinded to aspirin allocation, with study drug coding and delivery managed by research staff members at the study coordinating center.

A blinded Clinical End Points Committee the members of which did not participate in the study adjudicated all thrombotic events through to 30 days after surgery. Later thrombotic events were accepted if documented in the medical record or diagnosed by the treating physician. Study center visits with random audits and a Data Quality Committee monitored data completion and accuracy, and an independent Data Safety and Monitoring Committee monitored the study for safety.

\section{Measurements and Patient Follow-up}

Patient follow-up was planned for 30 days after surgery as previously reported, ${ }^{2,11}$ and at 1 year as presented here. Survival and clinical status was evaluated using a review of the medical records and patient contact via telephone. For myocardial infarction, stroke, or death occurring after 30 days through to 1 year after surgery, we required source documentation in the patient's medical record. If a patient informed us that the thrombotic event was managed at another hospital, we sought documentation via the patient or the patient's local medical practitioner.

Measurement of functional status at 1 year after surgery was based on the Katz independent activities of daily living (ADL) index, ${ }^{12}$ which originally included 3 categories representing degrees of function for each of the 6 ADL domains (moving in and out of a chair or bed, using the toilet, bathing or showering, walking across a room, eating, and dressing). For each domain, values of 2 points, 1 point, and 0 points for activities performed independently, with assist, or unable to perform, respectively. The ADL scale was administered to surviving patients via telephone at 12 months after surgery. A cumulative ADL score of 12 represented normal activities. Those with a score $<8$ were considered severely impaired. ${ }^{12,13}$ Further details are provided in the Online Data Supplement.

\section{Outcomes}

The primary outcome of the 1-year follow-up study was death or disability, the latter was defined as a surviving patient with a modified Katz ADL score $<8 .{ }^{12,14}$ The secondary end points were a composite and individual major adverse cardiovascular events (MACEs) that included nonfatal myocardial infarction or stroke, or death from any cause, through to 1 year after surgery. Postoperative myocardial infarction up to 30 days after surgery was defined according to the third 


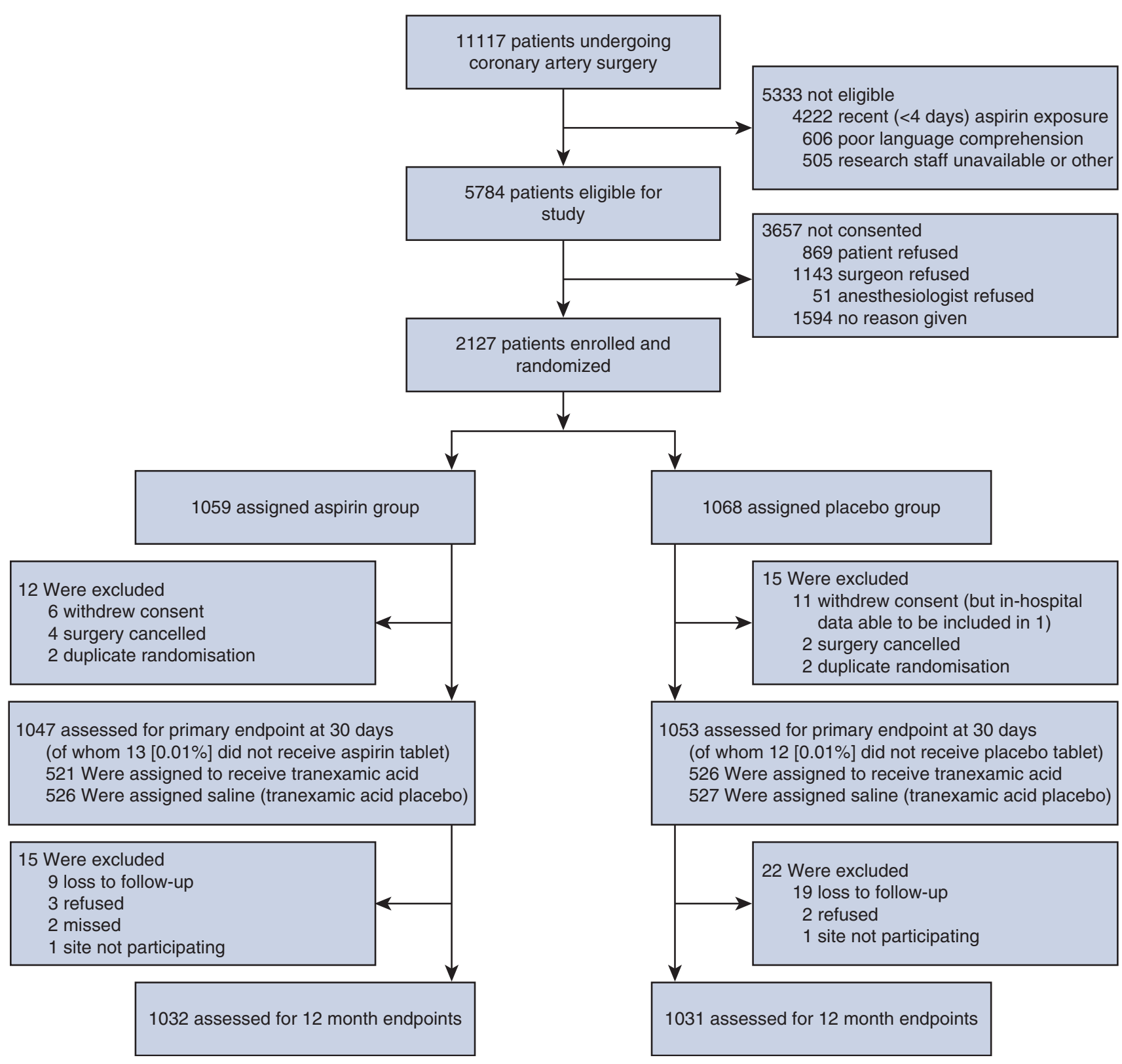

FIGURE 1. Enrollment, randomization, and assessment. One-year follow-up completed in $97 \%$ patients assigned aspirin or placebo.

universal definition, ${ }^{15}$ and in addition by markedly elevated cardiac biomarker levels in those recovering from isolated coronary artery bypass grafting surgery, as previously described, ${ }^{2}$ and subsequently through to 1 year only according to the third universal definition, ${ }^{15}$ adjudicated with source documentation. Stroke was defined by cerebral infarction or hemorrhage on computed tomography scan, or new neurologic signs lasting more than 24 hours, up to 30 days after surgery as described previously, ${ }^{2}$ and subsequently through to 1 year with source documentation. Further details are provided in the Online Data Supplement.

\section{Statistical Analysis}

The ATACAS trial was designed to achieve $90 \%$ power to detect a clinically important reduction in the primary end point of death and thrombotic events up to 30 days after surgery from $10 \%$ to $7 \% .{ }^{10}$ The aspirin comparison was terminated in July 2013 after enrolment of 2127 patients because of a low patient enrolment rate, but because of a higher than expected event rate $(19.6 \%)$ the trial had $>90 \%$ power for the primary end point. ${ }^{11}$ We did not estimate statistical power for the 1-year follow-up study but expected an event rate of at least $10 \%$ in the placebo group $^{16,17}$ and $30 \%$ effect size for our 1-year primary outcome.

Continuous data are reported as mean \pm standard deviation; categorical data are reported as frequency and percentage. The prespecified subgroups were patient sex, age, diabetes, previous myocardial infarction, unstable angina, surgical risk (based on the logistic European System for Cardiac Operative Risk Evaluation [EuroSCORE] score), left ventricular function, surgical bleeding risk, on-pump versus off-pump surgery, and aortic crossclamp time. Wald tests for risk ratios constructed from binomial regression with a logarithmic link were used to compare categorical data with results expressed as risk ratios with $95 \%$ confidence intervals (CIs). For the aspirin comparisons, 2 models were fitted for each outcome: the 
TABLE 1. Baseline patient and surgical characteristics of the 1-year cohort

\begin{tabular}{|c|c|c|}
\hline Characteristic & $\begin{array}{c}\text { Aspirin } \\
(\mathbf{n}=1032)\end{array}$ & $\begin{array}{c}\text { Placebo } \\
(\mathbf{n}=\mathbf{1 0 3 1})\end{array}$ \\
\hline Age (y) & $67.1 \pm 9.7$ & $66.8 \pm 10.1$ \\
\hline Weight (kg) & $85.1 \pm 16.4$ & $85.9 \pm 17.6$ \\
\hline Male & $858(83.1)$ & $840(81.5)$ \\
\hline \multicolumn{3}{|l|}{ NYHA functional class } \\
\hline I & $161(15.6)$ & $181(17.6)$ \\
\hline II & $571(55.3)$ & $566(55.0)$ \\
\hline III & $272(26.4)$ & $264(25.6)$ \\
\hline IV & $28(2.7)$ & $19(1.8)$ \\
\hline \multicolumn{3}{|l|}{ Pre-existing medical condition } \\
\hline Diabetes status & $341(33.0)$ & $357(34.6)$ \\
\hline Renal impairment & $69(6.7)$ & $80(7.8)$ \\
\hline Hypertension & 835 (80.9) & $827(80.2)$ \\
\hline Angina & 733 (71.0) & 739 (71.7) \\
\hline Heart failure & $135(13.1)$ & $131(12.7)$ \\
\hline Myocardial infarction & 357 (34.6) & $384(37.2)$ \\
\hline Endocarditis & $0(0.0)$ & $2(0.2)$ \\
\hline Cerebrovascular disease & $111(10.8)$ & $105(10.2)$ \\
\hline Peripheral vascular disease & $112(10.9)$ & $115(11.2)$ \\
\hline Pulmonary hypertension & $52(5.0)$ & $70(6.8)$ \\
\hline $\begin{array}{l}\text { Previous percutaneous transluminal } \\
\text { coronary angioplasty/stent }\end{array}$ & $8(0.8)$ & $9(0.9)$ \\
\hline Thrombolysis on this admission & $4(0.4)$ & $2(0.2)$ \\
\hline Smoking history & $694(67.2)$ & $685(66.4)$ \\
\hline Respiratory disease & $161(15.6)$ & $152(14.7)$ \\
\hline Chronic obstructive pulmonary disease & $107(10.4)$ & $99(9.6)$ \\
\hline \multicolumn{3}{|l|}{ Preoperative medications } \\
\hline $\begin{array}{l}\text { Angiotensin converting enzyme } \\
\text { inhibitor/angiotensin receptor blocker }\end{array}$ & $679(65.8)$ & $683(66.3)$ \\
\hline Beta-blocker & $662(64.1)$ & $647(62.8)$ \\
\hline Calcium channel blocker & $329(31.9)$ & $335(32.5)$ \\
\hline Nitrate & $436(42.2)$ & $440(42.7)$ \\
\hline Statin & 894 (86.6) & $875(84.9)$ \\
\hline Amiodarone & $10(1.0)$ & $17(1.6)$ \\
\hline Digoxin & $27(2.6)$ & $25(2.4)$ \\
\hline Diuretic & $236(22.9)$ & $250(24.2)$ \\
\hline Aspirin within $3 \mathrm{~d}$ & $1027(99.5)$ & $71(6.9)$ \\
\hline Clopidogrel within $7 \mathrm{~d}$ & $7(0.7)$ & $14(1.4)$ \\
\hline Warfarin within $7 \mathrm{~d}$ of surgery & $8(0.8)$ & $10(1.0)$ \\
\hline Heparin in previous $24 \mathrm{~h}$ & $37(3.6)$ & $36(3.5)$ \\
\hline Previous cardiac surgery & $17(1.6)$ & $14(1.4)$ \\
\hline \multicolumn{3}{|l|}{ Surgery status } \\
\hline Elective surgery & 915 (88.7) & $926(89.8)$ \\
\hline Isolated CABG & $762(73.8)$ & $782(75.8)$ \\
\hline Combined CABG-valve surgery & $231(22.4)$ & $207(20.1)$ \\
\hline On-pump surgery & $999(96.8)$ & $1001(97.1)$ \\
\hline Off-pump surgery & $33(3.2)$ & $28(2.7)$ \\
\hline Open chamber surgery & $251(24.3)$ & $229(22.2)$ \\
\hline \multicolumn{3}{|l|}{ Coronary artery grafting } \\
\hline No. of distal grafts & $3(2-4)$ & $3(2-4)$ \\
\hline Crossclamp time (min) & $67(48-91)$ & $66(47-91)$ \\
\hline
\end{tabular}

TABLE 1. Continued

\begin{tabular}{ccc}
\hline Characteristic & $\begin{array}{c}\text { Aspirin } \\
(\mathbf{n = 1 0 3 2})\end{array}$ & $\begin{array}{c}\text { Placebo } \\
(\mathbf{n}=\mathbf{1 0 3 1})\end{array}$ \\
\hline Internal mammary artery graft(s) & $923(89.7)$ & $937(91.1)$ \\
Postoperative aspirin within $24 \mathrm{~h}$ & $809(78.5)$ & $780(75.8)$ \\
\hline
\end{tabular}

Data are reported as mean \pm standard deviation, $\mathrm{n}(\%)$, or median (range). NYHA, New York Heart Association; $C A B G$, coronary artery bypass graft.

first included a term for the aspirin treatment group only; the second included an interaction term of aspirin with tranexamic acid exposure. We anticipated some missing outcome data in this study and so we performed a sensitivity analysis, adjusting for predictors of missing data. All $P$ values are 2 -sided and not adjusted for multiple comparisons.

\section{Role of the Funding Source}

The clinical trial was designed by the principal investigator (PSM). Study data were collected by research staff at each center, and monitored by the coordinating center in the Department of Anaesthesia and Perioperative Medicine at the Alfred Hospital, Melbourne, Australia, and analyzed by the study statistician (AF). Investigators (PSM, AF, and JS) prepared the first draft of the manuscript, which was then critically reviewed and edited by the other authors. The funding sources had no role in the design, conduct, analysis, or preparation of the manuscript. The authors had full access to all data and take full responsibility for the accuracy, completeness, and integrity of the reported analyses and data interpretation.

\section{RESULTS \\ Patient Enrollment and Follow-up}

Between March 2006 and January 2013, patients were randomized to aspirin (1059 patients) or placebo (1068 patients) in 22 centers in 6 countries (listed in the Online Data Supplement). One-year mortality outcomes were available for 2063 of the $2100(98.2 \%)$ patients with 30-day follow-up available (Figure 1). The patient and perioperative baseline characteristics for the 1-year cohort are presented in Table 1. All patients had 1 or more risk factors for surgery; $83 \%$ of the patients were men and the mean age was $67 \pm 10$ years. The median number of grafts was 3 (interquartile range, 2-4 grafts), with $90 \%$ of patients receiving at least 1 internal thoracic arterial graft. Postoperative aspirin therapy was commenced or recommenced within 24 hours of surgery in $77 \%$ of patients, and within 48 hours of surgery in $86 \%$ of patients. There were no significant differences at baseline between the 2 groups. Two study centers declined participation in the 1-year follow-up study and so their 3 patients were removed from the analysis. There were some statistically significantly differences in baseline characteristics when comparing those with and without 1-year follow-up outcome data (Tables E1 and E2).

\section{Primary Outcome}

Overall, there were 61 deaths $(2.9 \%)$ and a further 17 surviving patients with severe disability $(0.8 \%)$ through 


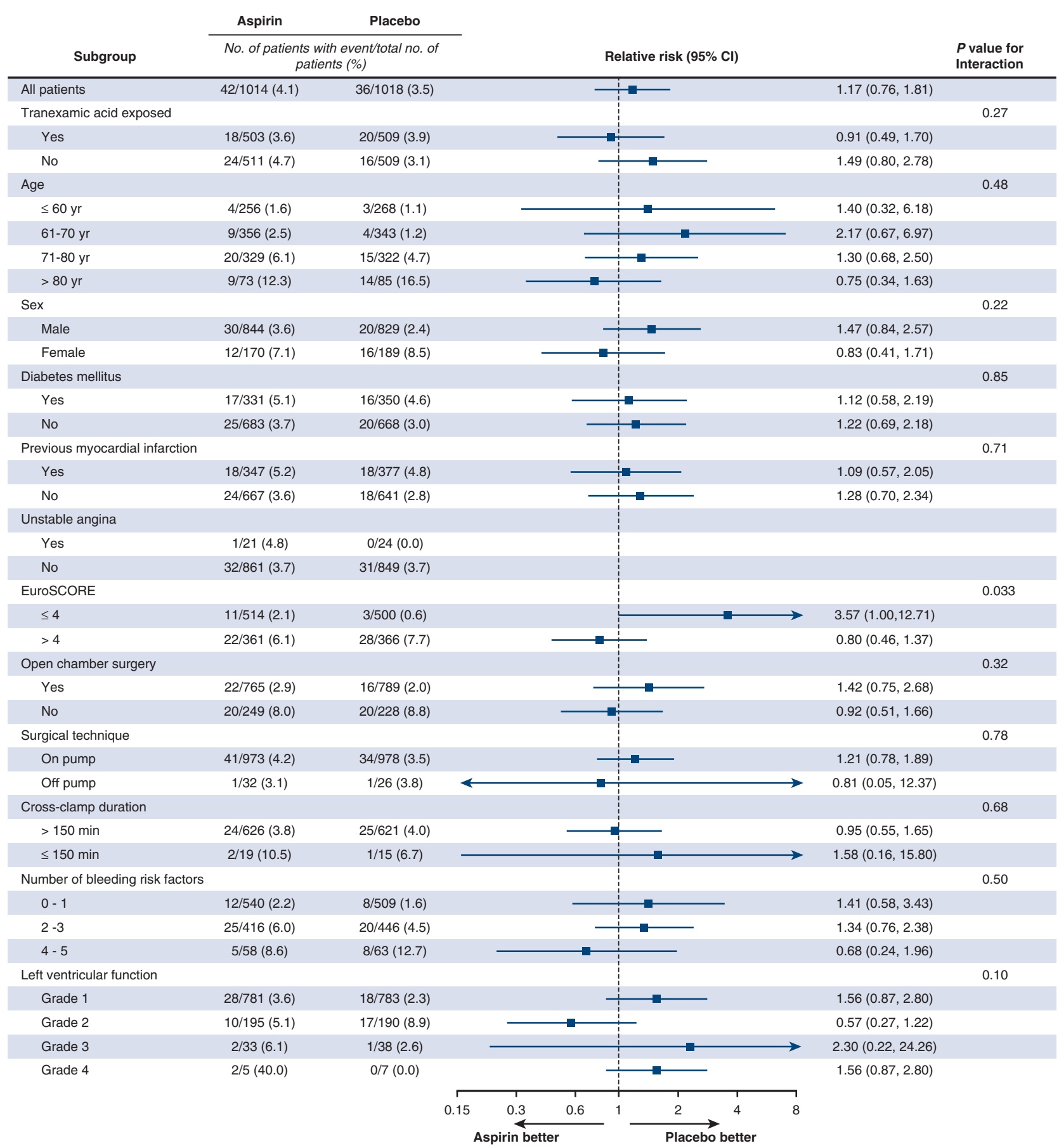

FIGURE 2. The relative reduction for the primary end point (death or disability) associated with aspirin in prespecified subgroups, expressed as relative risk ( $95 \%$ confidence inteval). EuroSCORE, European System for Cardiac Operative Risk Evaluation. *No $P$ value calculated for unstable angina because of 0 count in the placebo group.

to 1-year after surgery. The rate of death or severe disability was $4.1 \%$ in the aspirin group and $3.5 \%$ in the placebo group, risk ratio 1.17 (95\% CI, 0.76-1.81; $P=.48$ ). A sensitivity analysis to account for missing data did not meaningfully change these results (Tables E3 and E4). With the exception of those with a low EuroSCORE $(P=.030)$, there were no interaction effects with tranexamic acid exposure on these outcomes (Figure 2). In those with a EuroSCORE of 4 or less death or disability occurred in $2.1 \%$ of the patients in the aspirin group and in $0.6 \%$ of the patients in the placebo group $(P=.050)$. 
TABLE 2. One-year outcomes by aspirin group

\begin{tabular}{lcccc}
\hline \multicolumn{1}{c}{ Outcome } & Aspirin & Placebo & Relative risk $(\mathbf{9 5} \%$ confidence interval)* & $\boldsymbol{P}$ value \\
\hline $\begin{array}{l}\text { Primary outcome } \\
\text { Death or disability } \dagger\end{array}$ & $42 / 1014(4.1)$ & $36 / 1018(3.5)$ & $1.17(0.76-1.81)$ \\
Secondary outcome & & & & \\
Composite MACE & $183 / 1031(17.8)$ & $190 / 1030(18.4)$ & $0.96(0.80-1.16)$ & .48 \\
Myocardial infarction & $137 / 1013(13.5)$ & $163 / 1016(16.0)$ & $0.84(0.68-1.04)$ & .68 \\
Stroke & $27 / 1001(2.7)$ & $16 / 1014(1.6)$ & $1.71(0.93-3.15)$ & .11 \\
Death & $35 / 1027(3.4)$ & $26 / 1030(2.5)$ & $1.35(0.82-2.23)$ & .086 \\
\hline
\end{tabular}

Values are presented as $\mathrm{n} / \mathrm{N}(\%) . M A C E$, Major adverse cardiovascular event, consisting of myocardial infarction, stroke, or death from any cause. *Risk ratios from binary regression models with logarithmic link. †Disability is defined by a Katz activities of daily living score $<8$ (ie, severe).

\section{Secondary Outcomes}

There was no significant difference in the rate of MACE up to 1 year after surgery $(P=.68)$, or the individual rates of myocardial infarction $(P=.11)$, stroke $(P=.086)$, or death $(P=.24)$ up to 1 year after surgery (Table 2$)$. There was no evidence for an interaction between aspirin and tranexamic acid for the secondary outcomes (Tables 3 and E5). There were no significant interactions for MACE between treatment group and patient sex, age, left ventricle function, bleeding risk, surgical subtypes, and recent aspirin exposure (Figure E1).

A comparison between men and women identified a significantly higher rate of both death or disability, and MACE at 1 year after surgery, but these were not statistically significant after multivariable adjustment (Table E6).

\section{Updated Meta-Analysis}

Including these study results in an updated meta-analysis suggests that perioperative aspirin might reduce the rate of myocardial infarction (Figure 3, Video 1), but not overall MACE (Figure E2), up to 1 year after surgery.

\section{DISCUSSION}

This was the first large randomized trial to assess the effectiveness of aspirin exposure at the time of coronary artery surgery on longer-term outcomes. Our primary outcome measure was patient-centered (disability-free survival), supported by measurement of clinically important outcomes such as myocardial infarction, stroke and death. We did not identify a meaningful difference up to 1 year after surgery.

Several small randomized trials have found that aspirin reduced graft thrombosis in coronary artery surgery, $5,6,9$ and similar findings have been reported in a meta-analysis of trials across many types of surgery using vascular grafts (coronary, peripheral vascular, and renal). ${ }^{10}$ Gavaghan and colleagues ${ }^{5}$ investigated angiographic graft patency at 1 week (231 patients) and 1 year (219 patients) after coronary artery bypass surgery. The early and late vein graft occlusion rates were lower in aspirin-treated patients, $1.6 \%$ versus $6 \%(P=.004)$, and $6 \%$ versus $12 \%(P=.01)$, respectively. Others have reported similar results. ${ }^{6,18}$

A previous moderately sized $(n=783)$ randomized single-center trial in patients with stable coronary artery disease, comparing a single dose of aspirin, $300 \mathrm{mg}$, with placebo administered the night before coronary artery surgery, ${ }^{8}$ found on post hoc analysis that preoperative aspirin decreased the long-term risk of nonfatal coronary events (myocardial infarction or repeat revascularization) out to 3 years (hazard ratio, 0.58 ; $95 \%$ CI, 0.33-0.99). ${ }^{8}$ We could not replicate this finding but our results are consistent with a protective effect, with the point estimate

TABLE 3. Relative risks of 1-year outcomes for aspirin group according to tranexamic acid exposure

\begin{tabular}{|c|c|c|c|c|c|}
\hline \multirow[b]{2}{*}{ Outcome } & \multicolumn{2}{|c|}{ Randomized to aspirin and tranexamic acid } & \multicolumn{2}{|c|}{ Randomized to aspirin and placebo } & \multirow[b]{2}{*}{ Interaction $P$ value } \\
\hline & $\begin{array}{c}\text { Relative risk } \\
(95 \% \text { confidence interval })^{*}\end{array}$ & $P$ value & $\begin{array}{c}\text { Relative risk } \\
(95 \% \text { confidence interval })^{*}\end{array}$ & $P$ value & \\
\hline \multicolumn{6}{|l|}{ Primary end point } \\
\hline Death or disability $\dagger$ & $0.91(0.49-1.70)$ & .77 & $1.49(0.80-2.78)$ & .20 & .27 \\
\hline \multicolumn{6}{|l|}{ Secondary end point } \\
\hline Composite MACE & $0.96(0.73-1.27)$ & .78 & $0.96(0.75-1.23)$ & .76 & $>.99$ \\
\hline Myocardial infarction & $0.89(0.65-1.23)$ & .49 & $0.80(0.61-1.06)$ & .13 & .63 \\
\hline Stroke & $1.12(0.48-2.60)$ & .80 & $2.70(1.06-6.84)$ & .036 & .17 \\
\hline Death & $1.01(0.49-2.10)$ & .98 & $1.74(0.87-3.51)$ & .12 & .29 \\
\hline
\end{tabular}

MACE, Major adverse cardiovascular event, consisting of nonfatal and fatal myocardial infarction, nonfatal and fatal stroke, or death from any cause. *Relative risks from binary regression models with logarithmic link. Restricted to patients recruited before aspirin arm dropped and including an interaction between aspirin and tranexamic acid in the models. $\dagger$ Disability is defined by a Katz activities of daily living score $<8$ (ie, severe). 


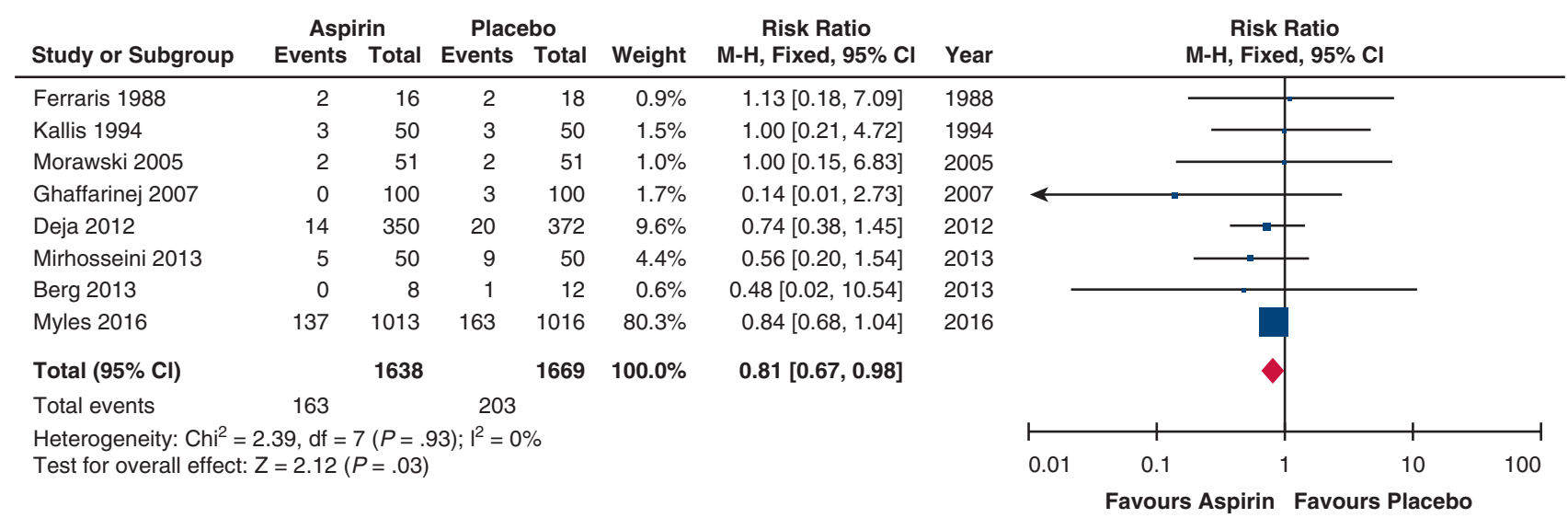

FIGURE 3. An updated meta-analysis of the effect of aspirin therapy on the 1-year risk of myocardial infarction in patients undergoing coronary artery surgery, including long-term follow-up studies (Deja and colleagues ${ }^{8}$ and Myles and colleagues ${ }^{2}$ ). *Deja and colleagues ${ }^{8}$ reported myocardial infarctions and revascularizations, so both included in this meta-analysis. $C I$, Confidence interval.

of effect for myocardial infarction $<1.0$. That is, we may have had insufficient statistical power to identify a small but clinically important effect for this end point. Our updated meta-analysis (Figure 3) supports this conjecture.

Early postoperative aspirin administration has been a standard of care in coronary artery surgery for many years. ${ }^{5,19}$ Small trials done in the 1980s found some evidence that preoperative aspirin might have a beneficial effect on venous and internal mammary artery grafts, ${ }^{6,18}$ but this does not seem to improve graft patency between 1 and 3 years after coronary artery surgery. ${ }^{9}$ Our 30 -day ${ }^{2}$ and 1-year results do not provide any compelling reason to either stop or continue aspirin before coronary artery surgery. But continuing aspirin therapy until surgery may decrease the chance of acute coronary events occurring in patients awaiting cardiac surgery in the community or hospital setting. ${ }^{20}$ Furthermore, an updated meta-analysis which included the 30-day ATACAS trial data (13 randomized trials, 4499 patients), found that continuing

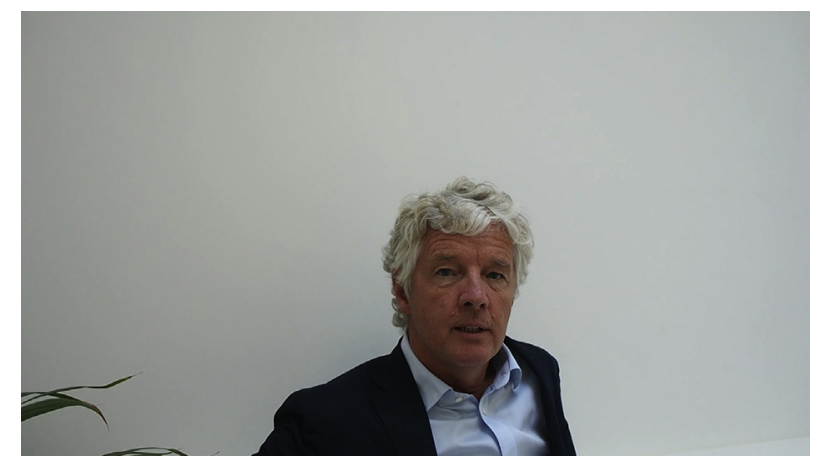

VIDEO 1. The lead author, Dr Paul Myles, discusses the overall results and clinical implications of the trial. Video available at: https://www. jtcvs.org/article/S0022-5223(18)32509-1/fulltext. aspirin up until the day of surgery reduced the risk of postoperative myocardial infarction (odds ratio, 0.79; 95\% CI, 0.64-0.99; $P=.04)$ without heterogeneity $\left(I^{2}=0\right)$ up to 30 days after surgery. ${ }^{21}$ We therefore recommend that aspirin should be continued in near-all patients having coronary artery surgery.

\section{Study Limitations}

Limitations of our study include a smaller than initially planned sample size that limited the likelihood of finding potentially significant differences in event rates. In the ATACAS trial, we evaluated an enteric-coated formulation of aspirin, $100 \mathrm{mg}$ given a few hours before surgery. A higher dose may provide greater antithrombotic effect but could expose the patient to greater risk of bleeding complications. Our 1-year follow-up study had some $(<2 \%)$ missing outcome data. We did not measure disability (Katz ADLs) scores preoperatively so we cannot be sure how much of the disability measured at 1 year was pre-existing. In view of the comparable functional status scores and comorbidities reported at baseline in the publications reporting 30-day results, ${ }^{2}$ it is unlikely there was any imbalance in rates of baseline disability. The expected incidence of death or disability at 1 year was $10 \%$, but the incidence was around 4\% (for MACE it was $18 \%$ ); this is likely to be underpowered for the primary outcome and so the results may be exposed to type II error. Some of the statistically significant findings may be exposed to type I error because of multiple testing.

\section{CONCLUSIONS}

We found that in patients undergoing coronary artery surgery, preoperative aspirin did not reduce disability-free 
survival or the rates of thrombotic events through to 1 year after surgery.

\section{Conflict of Interest Statement}

Bayer Pharma provided the aspirin and matched placebo tablets used in the study. All other authors have nothing to disclose with regard to commercial support.

The authors thank Adam Meehan for data management; Professors Andrew Tonkin, Henry Krum, and all members of the committees overseeing the trial; as well as the Australian and New Zealand College of Anaesthetists Clinical Trials Network.

\section{References}

1. Myles PS. Stopping aspirin before coronary artery surgery: between the devil and the deep blue sea. Circulation. 2011;123:571-3.

2. Myles PS, Smith JA, Forbes A, Silbert B, Jayarajah M, Painter T, et al. Stopping vs. continuing aspirin before coronary artery surgery. N Engl J Med. 2016;374: 728-37.

3. Gaudino M, Antoniades C, Benedetto U, Deb S, Di Franco A, Di Giammarco G, et al. Mechanisms, consequences, and prevention of coronary graft failure. Circulation. 2017;136:1749-64.

4. Hillis LD, Smith PK, Anderson JL, Bittl JA, Bridges CR, Byrne JG, et al. 2011 ACCF/AHA guideline for coronary artery bypass graft surgery: a report of the American College of Cardiology Foundation/American Heart Association task force on practice guidelines. Circulation. 2011;124:e652-735.

5. Gavaghan TP, Gebski V, Baron DW. Immediate postoperative aspirin improves vein graft patency early and late after coronary artery bypass graft surgery. A placebo-controlled, randomized study. Circulation. 1991;83:1526-33.

6. Goldman S, Copeland J, Moritz T, Henderson W, Zadina K, Ovitt T, et al. Improvement in early saphenous vein graft patency after coronary artery bypass surgery with antiplatelet therapy: results of a veterans administration cooperative study. Circulation. 1988;77:1324-32

7. Mangano D. Aspirin and mortality from coronary bypass surgery. $N$ Engl J Med. 2002;347:1309-17.

8. Deja MA, Kargul T, Domaradzki W, Stacel T, Mazur W, Wojakowski W, et al Effects of preoperative aspirin in coronary artery bypass grafting: a doubleblind, placebo-controlled, randomized trial. J Thorac Cardiovasc Surg. 2012; 144:204-9.

9. Goldman S, Copeland J, Moritz T, Henderson W, Zadina K, Ovitt T, et al Long-term graft patency (3 years) after coronary artery surgery. Effects of aspirin: results of a VA Cooperative study. Circulation. 1994;89:1138-43.
10. Myles P, Smith J, Knight J, Cooper D, Silbert B, McNeil J, et al. Aspirin and tranexamic acid for coronary artery surgery (ATACAS) trial: rationale and design. Am Heart J. 2008; 155:224-30.

11. Myles PS, Smith JA, Forbes A, Silbert B, Jayarajah M, Painter T, et al. Tranexamic acid in patients undergoing coronary-artery surgery. $N$ Engl J Med. 2017; 376:136-48.

12. Katz S, Ford AB, Moskowitz RW, Jackson BA, Jaffe MW. Studies of illness in the aged. The index of adl: a standardized measure of biological and psychosocial function. JAMA. 1963;185:914-9.

13. Katz S, Downs TD, Cash HR, Grotz RC. Progress in development of the index of ADL. Gerontologist. 1970;10:20-30.

14. Williams MR, Wellner RB, Hartnett EA, Thornton B, Kavarana MN, Mahapatra R, et al. Long-term survival and quality of life in cardiac surgical patients with prolonged intensive care unit length of stay. Ann Thorac Surg. 2002; 73:1472-8

15. Thygesen K, Alpert JS, Jaffe AS, Simoons ML, Chaitman BR, White HD, et al. Third universal definition of myocardial infarction. Circulation. 2012;126: 2020-35.

16. Shahian DM, O'Brien SM, Sheng S, Grover FL, Mayer JE, Jacobs JP, et al. Predictors of long-term survival after coronary artery bypass grafting surgery: results from the Society of Thoracic Surgeons adult cardiac surgery database (the ASCERT study). Circulation. 2012;125:1491-500.

17. Morice MC, Serruys PW, Kappetein AP, Feldman TE, Stahle E, Colombo A, et al. Outcomes in patients with de novo left main disease treated with either percutaneous coronary intervention using paclitaxel-eluting stents or coronary artery bypass graft treatment in the synergy between percutaneous coronary intervention with TAXUS and cardiac surgery (SYNTAX) trial. Circulation. 2010;121:2645-53.

18. Hockings BE, Ireland MA, Gotch-Martin KF, Taylor RR. Placebo-controlled trial of enteric coated aspirin in coronary bypass graft patients. Effect on graft patency. Med J Aust. 1993;159:376-8.

19. Ferraris VA, Ferraris SP, Moliterno DJ, Camp P, Walenga JM, Messmore HL, et al. The Society of Thoracic Surgeons practice guideline series: aspirin and other antiplatelet agents during operative coronary revascularization (executive summary). Ann Thorac Surg. 2005;79:1454-61.

20. Burger W, Chemnitius JM, Kneissl GD, Rucker G. Low-dose aspirin for secondary cardiovascular prevention - cardiovascular risks after its perioperative withdrawal versus bleeding risks with its continuation - review and meta-analysis. J Intern Med. 2005;257:399-414.

21. Hastings S, Myles PS, McIlroy DR. Aspirin and coronary artery surgery: an updated meta-analysis. Br J Anaesth. 2016;116:716-7.

Key Words: anesthesia, antiplatelet, disability-free survival, major adverse cardiac events, outcome 